\title{
Posterior Fossa Extradural Haematomas (PFEDH) at apex trauma center: A retrospective study
}

\author{
Anuj Kumar Tripathi ${ }^{1 *}$, Vishal Singh ${ }^{2}$ \\ ${ }^{\mathbf{1}}$ Assistant Professor, ${ }^{2}$ Statistician Cum Data Analyst, Dept. of General Surgery, Career Institute of Medical Sciences and Hospital, \\ Lucknow, Uttar Pradesh, India
}

*Corresponding Author: Anuj Kumar Tripathi

Email: dranujkumartripathi@gmail.com

\begin{abstract}
Extradural haematomas of the posterior fossa are a rare in comparison to supratentorial epidural hematomas and much less common. Because of the limited size of the posterior fossa early identification and intervention can save the lives of these patients.
\end{abstract}

Keywords: Road side accident, Posterior fossa haematoma, Extradural haematoma.

\section{Introduction}

Extradural haematomas of the posterior fossa are a rare in comparison to supratentorial epidural hematomas and much less common in most series, posterior fossa extradural haematomas (PFEDH) themselves account for $4 \%$ to $12.9 \%$ of all EDH. ${ }^{1-3}$ Despite the rarity of these lesions, timely recognition and surgical evacuation is necessary because of the limited size of the posterior fossa.

\section{Materials and Methods}

This is a retrospective study of 8 patients of posterior fossa extradural haematoma (PFEDH) admitted between from September 2018 to February 2020 in career institute of medical sciences and hospital, Lucknow.

\section{Results}

All admitted cases are male with age range between 18 years to 45 years mode of accident in all these cases were road side accident in these cases posterior fossa extradural haematoma (PFEDH) was compressing the brain stem with associated hydrocephalus. Glasgow coma scale (GCS) score were given in table 1 .

\section{Table 1}

\begin{tabular}{|l|c|}
\hline GCS score & Cases \\
\hline $13-15$ & Nil \\
\hline $9-12$ & 6 \\
\hline 8 Or less than 8 & 2 \\
\hline
\end{tabular}

Presenting features in these cases were given in table 2.
Table 2

\begin{tabular}{|l|c|c|}
\hline S. No. & Complaint & Numbers of cases \\
\hline 1 & vomiting & 5 \\
\hline 2 & Ear bleed & 2 \\
\hline 3 & Altered sensorium & 8 \\
\hline 4 & irritability & 6 \\
\hline
\end{tabular}

All these case were operated as soon as possible. Post surgical complication were given in table 3 .

Table 3

\begin{tabular}{|l|c|c|}
\hline S. No. & Complication & Numbers of cases \\
\hline 1 & Rebleed & 1 \\
\hline 2 & $\begin{array}{c}\text { Operation side } \\
\text { collection }\end{array}$ & 3 \\
\hline 3 & tracheostomy & 1 \\
\hline
\end{tabular}

Rebleed case was operated again and post operative computed tomography scan shows no collection. Operation side collections were aspirates and crepe bandage was applied. In one case intraoperative tracheostomy was done which was removed on postoperative day 3. No mortality and infection were seen in these cases. Average hospital stay was 8 days.

\section{Discussion}

Patients of posterior fossa EDH are prone to rapid deterioration. PFEDH themselves account for $4 \%$ to $12.9 \%$ of all EDH. ${ }^{1-3}$ Despite the rarity of these lesions, timely recognition and surgical evacuation is necessary because of the limited size of the posterior fossa. Surgical evacuation of posterior fossa epidural hematoma involves a occipital craniotomy or craniectomy using drill/ burr holes \& Gigli 
saw. In the literature the mortality in posterior fossa EDH ranges from $4 \%$ to $26.5 \%$. $^{5-7}$

\section{Conclusion}

Patients with posterior fossa EDH with mass effect over brain stem and hydrocephalus should undergo evacuation of hematoma as early as possible.

\section{Source of Funding}

None.

\section{Conflict of Interest}

None.

\section{References}

1. Mahajan RK, Sharma BS, Khosla VK. Posterior fossa extradural haematoma - experience of nineteen cases. Ann Acad Med Singapore. 1993;22(3 Suppl):410-3.

2. Wang E C M, Lim AYT, Yeo TT. Traumatic Posterior Fossa Extradural Haematomas (PFEDH). Singapore Med J. 1998;9(3):107-11.
3. Garza-Mercado R. Extradural haematoma of the posterior cranial fossa: Report of seven cases with survival. $J$ Neurosurg. 1983;59:664-72.

4. Bor-Seng-Shu E, Aguiar PH, Matushita H, Manreza LA, Ferreira AA. Actual asymptomatic epidural hematomas in childhood. Report of three cases. Childs Nerv Syst. 1997;13:605-7.

5. Ersahin Y, Mutluer S. Posterior fossa extradural hematomas in children. Pediatr Neurosurg. 1993;19:31-3.

6. Van den Brink WA, Zwienenberg M, Zandee SM, van der Meer L, Maas AIR, Avezaat CJJ. The prognostic importance of the volume of traumatic epidural and subdural haematomas revisited. Acta Neurochir(Wien). 1999;141:509-14.

How to cite this article: Tripathi AK, Singh V. Posterior Fossa Extradural Haematomas (PFEDH) at apex trauma center: A retrospective study. IP Indian $J$ Anat Surg Head Neck Brain. 2020;6(1):25-6. 